\title{
RESPONSE OF MOUSE OVARIES IN VIVO AND IN ORGAN CULTURE TO PREGNANT MARE'S SERUM GONADOTROPHIN AND HUMAN CHORIONIC GONADOTROPHIN
}

\author{
III. EFFECT OF AGE \\ P. NEAL AND T. G. BAKER \\ Hormone Laboratory, Department of Obstetrics and Gynaecology, \\ University of Edinburgh, Edinburgh EH3 9ER
}

(Received 12th February 1974)

The response of the ovary to exogenous gonadotrophins is known to be dependent upon the age of the animal at the time of treatment (Zarrow \& Wilson, 1961; McLaren, 1967). The present experiments were carried out to reinvestigate this phenomenon in intact mice and to determine whether this relationship also holds when mouse ovaries are treated with PMSG and HCG in organ culture.

For the in-vitro studies, mice of the Schofield albino strain aged 14, 21, 28, 35 or 49 days post partum (p.p.) were killed by dislocation of the neck and their ovaries were cleanly dissected free from adnexa. The technique for organ culture has been described in full in our earlier papers (Baker \& Neal, 1969, 1972). At the onset of culture, PMSG ('Gestyl': Organon Laboratories, London) was added to the Petri dishes containing the ovaries at a concentration of 0.6 i.u. $/ \mathrm{ml}$ ( 3 i.u. in $5 \mathrm{ml} \mathrm{medium):} \mathrm{the} \mathrm{nutrient} \mathrm{medium} \mathrm{was} \mathrm{completely} \mathrm{replaced} 48 \mathrm{hr}$ later with fresh fluid containing HCG ('Pregnyl': Organon) at a dose of 0.4 i.u./ml. After $24 \mathrm{hr}$ of culture with HCG, the explants were fixed in Bouin's aqueous fluid, dehydrated with ethanol and embedded in paraffin wax. Serial sections cut at 5 to $7 \mu \mathrm{m}$ were stained with Harris's haematoxylin and eosin.

Animals in the coeval control groups were given intraperitoneal injections of 3.0 i.u. PMSG at the same ages as in the culture experiments, followed $48 \mathrm{hr}$ later by treatment with 2.0 i.u. HCG. The animals were killed $24 \mathrm{hr}$ later and their ovaries, with associated oviducts, were fixed for histology using identical procedures to those employed for the organ-culture groups (see above).

Serial sections of the control and cultured ovaries were examined with the microscope and counts were made of those follicular oocytes which were undergoing preovulatory maturation beyond the dictyate (diffuse diplotene or 'resting') stage. In addition, the number of ovulated eggs within the oviducts of the controls was assessed. As in our previous experiments (e.g. Baker \& Neal, 1972; Neal \& Baker, 1973, 1974), the oocytes were arbitrarily classified as 'metaphase I' (including anaphase I and telophase), 'metaphase II' (follicular oocytes), and 'ovulated eggs' (in the oviducts).

The histological appearance of the explanted ovaries closely resembled that 
of the coeval controls which had been treated with the same hormones: the follicles and the oocytes within them showed no abnormalities or signs of degeneration. Precise counts of the total population of Graafian (antral) follicles were not carried out: we gained the impression, however, that these were less numerous in the cultured ovaries than they were in vivo (see also Neal \& Baker, 1974).

The total number of oocytes undergoing preovulatory maturation and ovulation in vivo was found to fluctuate with age. Ovaries from mice aged 14 days $p . p$. did not respond to the hormones, whereas a maximal effect was obtained with animals aged 28 days (see Table 1). These results are similar to those of Zarrow \& Wilson (1961).

Table 1. The effect of age on the number of mouse oocytes undergoing preovulatory maturation in response to treatment with PMSG and HCG in vivo

\begin{tabular}{c|c|c|c|c|c}
\hline & & \multicolumn{4}{|c}{ No. of oocytes maturing/ovary* } \\
$\begin{array}{c}\text { Age } \\
\text { (days) }\end{array}$ & $\begin{array}{c}\text { No. of ovaries } \\
\text { per group }\end{array}$ & 'Metaphase I' & 'Metaphase II' & Ovulated & Total \\
\hline 14 & 5 & $0 \cdot 0$ & $0 \cdot 0$ & $0 \cdot 0$ & $0 \cdot 0$ \\
21 & 8 & $10 \cdot 0 \pm 2 \cdot 0$ & $4 \cdot 1 \pm 0.9$ & $4 \cdot 6 \pm 1 \cdot 0$ & $18 \cdot 8 \pm 2 \cdot 1$ \\
28 & 8 & $12 \cdot 2 \pm 1 \cdot 2$ & $7 \cdot 5 \pm 1 \cdot 5$ & $10 \cdot 5 \pm 2 \cdot 5$ & $30 \cdot 2 \pm 4 \cdot 0$ \\
35 & 10 & $8 \cdot 3 \pm 1 \cdot 6$ & $4 \cdot 4 \pm 0 \cdot 9$ & $3 \cdot 3 \pm 0 \cdot 6$ & $16 \cdot 0 \pm 1.9$ \\
49 & 12 & $4 \cdot 2 \pm 0.9$ & $4 \cdot 2 \pm 0 \cdot 7$ & $5 \cdot 9 \pm 0 \cdot 9$ & $14 \cdot 3 \pm 1 \cdot 4$ \\
\hline
\end{tabular}

* Mean \pm S.E.

The number of oocytes undergoing preovulatory maturation in response to PMSG and HCG administered in organ culture was much lower than in vivo and ovulation did not occur (Table 2; see also Baker \& Neal, 1972). The peak response occurred at 21 days p.p. (cf. 28 days in vivo), but was only half the control value (Table 2 ; cf. Table 1 ). This reduced response to gonadotrophic hormones in organ culture was almost certainly due to an insufficient stimulation of follicular growth by PMSG since we have shown previously that HCG is equally effective in vivo and in organ culture (Baker \& Neal, 1972; Neal \&

Table 2. The effect of age on the number of mouse oocytes undergoing preovulatory maturation in response to treatment with PMSG and HCG in vitro

\begin{tabular}{c|c|c|c|c}
\hline \multirow{2}{*}{$\begin{array}{c}\text { Age } \\
\text { (days p.p.) }\end{array}$} & $\begin{array}{c}\text { No. of ovaries } \\
\text { per group }\end{array}$ & \multicolumn{3}{|c}{ No. of oocytes maturing/ovary* } \\
\cline { 2 - 5 } & 'Metaphase I' & 'Metaphase II' & Total \\
\hline 14 & 8 & $0 \cdot 0$ & $0 \cdot 0$ & $0 \cdot 0$ \\
21 & 7 & $7 \cdot 0 \pm 1 \cdot 1$ & $2 \cdot 5 \pm 1 \cdot 0$ & $9 \cdot 7 \pm 1 \cdot 8$ \\
28 & 11 & $2 \cdot 4 \pm 0 \cdot 6$ & $0 \cdot 6 \pm 0 \cdot 4$ & $3 \cdot 0 \pm 0 \cdot 7$ \\
35 & 8 & $2 \cdot 7 \pm 0 \cdot 6$ & $0 \cdot 5 \pm 0 \cdot 3$ & $3 \cdot 2 \pm 0 \cdot 6$ \\
49 & 8 & $2 \cdot 7 \pm 1 \cdot 0$ & $1 \cdot 4 \pm 0 \cdot 8$ & $4 \cdot 1 \pm 1 \cdot 8$ \\
\hline \multicolumn{4}{c}{ p.p., post partum. } \\
* Mean \pm S.E.
\end{tabular}


Baker, 1973, 1974). Both PMSG and FSH induce mitotic divisions in granulosa cells within ovaries maintained in organ culture (Pavic, 1963; Fainstat, 1968; Ryle, 1971), but it remains to be established whether these hormones are equally effective in inducing normal development of the follicle.

Peters (1969) has shown that type 5b and 6 follicles (which first appear on Day $14 p . p$.) reach maximum numbers on Day 21, whereas mature preovulatory follicles are most numerous on about Day 30 in mice of the Street strain. It is possible, therefore, that PMSG administered in vitro is ineffective in inducing the final 'wave' of follicular growth beyond stage 5; this could account for the smaller size of the follicles in the explanted ovaries. The markedly reduced population of oocytes undergoing meiotic maturation in organ culture could thus be due to the failure of PMSG to provide sufficient antral follicles for response to the HCG.

It is probable that FSH would be more effective in inducing follicular growth in the explanted ovaries than PMSG. Pedersen (1970) has shown that FSH acts on all follicles larger than type $3 \mathrm{~b}$ in intact mice and thus the population of follicles that can respond to HCG should be increased. Further experiments are being carried out to test this hypothesis.

It can be concluded that PMSG at the doses and duration of treatment used in the present study has little effect on follicular growth in vitro. The maturation of oocytes in response to HCG appears to be dependent upon the availability of antral follicles at the onset of culture, which in turn is dependent upon the age of the animal from which the ovaries were recovered. The present results are similar to those of Rowlands \& Williams (1943) and Rowlands (1944) who showed that injections of PMSG into hypophysectomized rats were ineffective in restoring the normal population of follicles within the ovary.

The expenses incurred in the present study were defrayed from a grant to T.G.B. by the Population Council, New York. The hormones were generously provided by Organon Laboratories Ltd.

\section{REFERENCES}

BAKER, T. G. \& NEAL, P. (1969) The effect of X-irradiation on mammalian oocytes in organ culture Biophysik, 6, 39.

BAKER, T. G. \& NEAL, P. (1972) Gonadotrophin-induced maturation of mouse Graafian follicles in organ culture. In Oogenesis, p. 377. Eds. J. D. Biggers and A. W. Schuetz. University Park Press, Baltimore.

Fainstat, T. (1968) Organ culture of postnatal rat ovaries in chemically defined medium. Fert. Steril. $19,317$.

McLAREN, A. (1967) Factors affecting the variation in response of mice to gonadotrophic hormones. 7. Endocr. 37, 147.

NeAL, P. \& BakER, T. G. (1973) Response of mouse ovaries in vivo and in organ culture to pregnant mare's serum gonadotrophin and human chorionic gonadotrophin. I. Examination of critical time intervals. F. Reprod. Fert. 33, 399.

NeAl, P. \& BAKER, T. G. (1974) Response of mouse ovaries in vivo and in organ culture to pregnant mare's serum gonadotrophin and human chorionic gonadotrophin. II. Effect of different doses of hormones. $\mathcal{F}$. Reprod. Fert. 37, 399.

PAvic, D. (1963) The effect of gonadotrophic hormones on young rat ovaries grown in organ culture. 7. Endocr. 26, 531.

Pedersen, T. (1970) Cell population kinetics of the ovary of the immature mouse after FSH stimulation. In Gonadotrophins and Ovarian Development, p. 312. Eds. W. R. Butt, A. G. Crooke and M. Ryle. Livingstone, Edinburgh. 
Peters, H. (1969) The development of the mouse ovary from birth to maturity. Acta endocr., Copenh. $62,98$.

Rowzands, I. W. (1944) The production of ovulation in the immature rat. F. Endocr. 3, 384.

Rowlands, I. W. \& Williams, P. C. (1943) Production of ovulation in hypophysectomized rats. $\mathcal{F}$. Endocr. 3, 310.

RYLE, M. (1971) The activity of human follicle-stimulating hormone preparations as measured by a response in vitro. F. Endocr. 51, 97.

Zarrow, M. X. \& WiLson, E. D. (1961) The influence of age on superovulation in the immature rat and mouse. Endocrinology, 69, 851 . 